\title{
Avaliação do uso de agente lastrante no controle do intumescimento filamentoso em sistema de lodos ativados utilizando efluentes de fábrica de papel reciclado
}

\author{
Evaluation of the use of ballasting agent for filamentous bulking control \\ in activated sludge treatment process using effluent
}

\author{
Hygor Aristides Victor Rossoni | Ana Augusta Passos Resende \\ Ann Honor Mounteer | Cláudio Arcanjo de Sousa | Cláudio Mudado Silva \\ José Lívio Gomide | Mônica de Abreu Azevedo \\ Grupo de pesquisa vinculado à Universidade Federal de Viçosa (UFV)*
}

Data de entrada: 02/08/2012 | Data de aprovação: 17/09/2012

\begin{abstract}
Resumo
Com o objetivo de testar o uso de agente lastrante - talco - para o controle do intumescimento filamentoso do lodo, foi utilizado lodo biológico com alto teor de bactérias filamentosas da espécie Tipo $021 \mathrm{~N}$ obtido de uma fábrica de papel reciclado. O experimento consistiu de um sistema de tratamento biológico em batelada, operado com uma idade de lodo de dez dias. Foram construídos cinco reatores biológicos e dosadas diferentes concentrações de talco: 0\%, 25\%, 50\%, 75\% e 100\% em relação aos sólidos suspensos totais no tanque de aeração. Adições sucessivas de talco contribuíram para a redução do índice volumétrico do lodo, sendo que as dosagens de 75\% e 100\% foram as mais eficientes. A presença do talco não interferiu na atividade biológica, no entanto, verificou-se a necessidade de promover um maior descarte de lodo para a manutenção de condições operacionais. A adição do talco teve efeito temporário, sendo necessárias repetidas adições para manutenção de baixo índice volumétrico do lodo.
\end{abstract}

Palavras-chave: agente lastrante; intumescimento filamentoso; lodos ativados; índice volumétrico do lodo.

\begin{abstract}
The objective of this study was to test the use of ballasting agent - talc - for the control of filamentous bulking. The bio-sludge used was obtained from a recycling paper mill and had an abundance of filamentous bacteria Type 021N. The experiment consisted of five bioreactors operating batch mode with sludge age of ten days. Different talc applications were used: 0\%, 25\%, 50\%, 75\% and 100\% in relation to the total suspended solids in the aeration tank. The following analyses were carried out to monitor the system: suspended solids, sludge volumetric index (SVI) and chemical oxygen demand. Successive additions of talc contributed for the reduction of SVI. Dosages of 75\% and 100\% showed to be most efficient to improve settleability of the sludge. The presence of talc did not interfere with biological activity of the sludge. However, it was observed an increase of the total suspended solid concentration in the aeration tank. The addition of talc had a temporary effect on sludge settleability, so it was necessary to add repeatedly talc in the reactor in order to maintain a low filamentous bulking.
\end{abstract}

Key-words: ballasting agent; filamentous bulking; activated sludge; sludge volumetric index.

\footnotetext{
*Curriculum dos autores - ver página 72
} 


\section{Introdução}

Nas últimas décadas, as fábricas de celulose e papel vêm buscando reduzir o consumo de água e, consequentemente, o volume gerado de efluentes líquidos a serem tratados e lançados no meio ambiente. Não somente por pressões ambientais, mas, sobretudo por questões econômicas, tais esforços tendem a ser intensificados em um futuro próximo.

O processo de tratamento dos efluentes de fábricas de celulose e papel mais comumente utilizado no mundo é o de lodos ativados (POKHREL e VIRARAGHAVAN, 2004; AGRIDIOTIS et al. 2006). Consiste basicamente de um reator aeróbio, onde ocorre a oxidação da matéria orgânica e a síntese de novas células na presença de uma população diversificada de microrganismos (biomassa), formada principalmente por bactérias, protozoários, rotíferos e fungos, seguido de um decantador secundário que separa a fase líquida da fase sólida e uma linha de recirculação do lodo do decantador secundário para o reator, que tem como objetivo manter uma elevada concentração de biomassa no reator biológico (PACHECO e PESSÔA, 2009; SANT'ANNA JUNIOR, 2010).

Um problema operacional bastante comum nos sistemas de lodos ativados está relacionado à separação da biomassa microbiana do meio líquido no decantador secundário, sendo este problema principalmente relacionado aos parâmetros biológicos, ou seja, à formação de flocos de biomassa (LOURES, 2007; SOUSA, 2008).

Quando o lodo biológico apresenta um equilíbrio entre as bactérias filamentosas e as formadoras de flocos, a biomassa é separada do efluente com facilidade. Por outro lado, havendo pouca ou nenhuma ocorrência de bactérias filamentosas, o floco perde sua resistência às tensões de cisalhamento provocadas pela turbulência da aeração, dando origem a um floco pequeno e frágil, de difícil decantação. Lodos biológicos com predominância dos organismos filamentosos levam ao aparecimento de flocos volumosos e de difícil separação no decantador secundário. Este fenômeno é conhecido como intumescimento do lodo, ou na expressão inglesa: "bulking" filamentoso (MARTINS et al. 2004).

O floco biológico intumescido é menos denso e não sedimenta na unidade de decantação secundária, levando, assim, a perdas de biomassa no efluente tratado e menor eficiência na remoção de compostos orgânicos, o que resulta em baixa qualidade do efluente tratado.

Existem diversos estudos envolvendo o controle do intumescimento do lodo, que consistem, principalmente, em corrigir as causas do crescimento excessivo das bactérias filamentosas ou em criar condições favoráveis ao crescimento das bactérias formadoras de flocos. Como exemplo de uso de medidas preventivas no controle do intumescimento do lodo, pode-se citar a otimização de parâmetros operacionais da estação de tratamento de efluentes (ETE) (METCALF \& EDDY, 2003), como: idade do lodo, controle de $\mathrm{pH}$, concentração de nutrientes, uso de seletores biológicos e outras.

Já em casos em que ocorre o intumescimento severo do lodo, pode ocorrer a perda da eficiência de tratamento e de clarificação do efluente tratado. Neste caso, o uso de medidas agudas que aumentam prontamente a sedimentabilidade do lodo torna-se necessário. Dentre essas medidas, podem ser citadas, conforme estudos reportados por Jenkins et al. (2003) e Mamais et al. (2011), uso de agentes biocidas (compostos oxidantes), agentes lastrantes (talco) e agentes floculantes e coagulantes (polímeros sintéticos).

A função básica da adição de agentes lastrantes no reator biológico em um tratamento de efluentes por lodos ativados é aumentar a densidade e o tamanho do floco biológico, melhorando a sedimentação do lodo na unidade de decantação.

Apesar de alguns estudos (GRAJA et al., 1998; PIIRTOLA, et al., 1999(a); PIIRTOLA, et al., 1999(b); SEKA, et al., 2000; AGRIDIOTIS, et al., 2006) mostrarem uma expressiva influência de agentes lastrantes - entre estes o uso de talco -, no controle do "bulking" filamentoso, por meio da redução do índice volumétrico do lodo (IVL), o número de trabalhos dedicados a este tema ainda é muito reduzido, mesmo mundialmente, sendo esta carência ainda mais expressiva para as condições brasileiras. Além disso, existe uma deficiência de informações sobre a dosagem ótima e o seu efeito sobre população microbiológica do tratamento de efluentes.

Cabe destacar que o talco é um insumo utilizado na indústria de papel, empregado como carga e como pigmento alvejante quando incorporados à massa celulósica. Como principais características, o talco deve ser livre de impurezas, apresentando coloração ou alvura aceitável, ter alto índice de refração para uma boa opacidade e ser quimicamente inerte, evitando reações com outros materiais usados na fabricação ou uso do papel (CAMARA, 2003).

Além da melhoria da qualidade do papel, o uso do talco traz benefícios significativos no processo produtivo, dentre os quais pode ser destacado que o 
maior teor de mineral no papel implica na diminuição da quantidade de fibras celulósicas, o que, também, acarreta em economia de energia na secagem do papel (CRUZ et al. 2006).

Com base nesta perspectiva, o principal objetivo do presente trabalho foi testar o uso de talco para o controle do intumescimento filamentoso utilizando lodo biológico e águas residuárias provenientes de uma Indústria de Papel Reciclado. Buscou-se avaliar as concentrações ou dosagens ótimas de aplicação do talco e verificar o seu efeito sobre o sistema laboratorial de tratamento de efluentes.

\section{Metodologia}

Visando verificar a influência do uso de talco para o controle do intumescimento filamentoso do lodo, utilizou-se tratamento biológico laboratorial constituído de um sistema de lodos ativados de alimentação intermitente, denominados "reatores em batelada sequencial" (RBS), mantendo o tempo de retenção hidráulica compatível com o sistema convencional de lodos ativados.

Os biorreatores foram constituídos frascos de PVC de $3.000 \mathrm{~mL}$, com um volume útil de 2.000 $\mathrm{mL}$, equipados com difusores de ar, os quais foram suficientes para a agitação mecânica e para o suprimento de oxigênio necessário ao tratamento aeróbio dos efluentes, e, mantidos em temperatura controlada de $35^{\circ} \mathrm{C}$.

Foram realizados testes com o talco em cinco

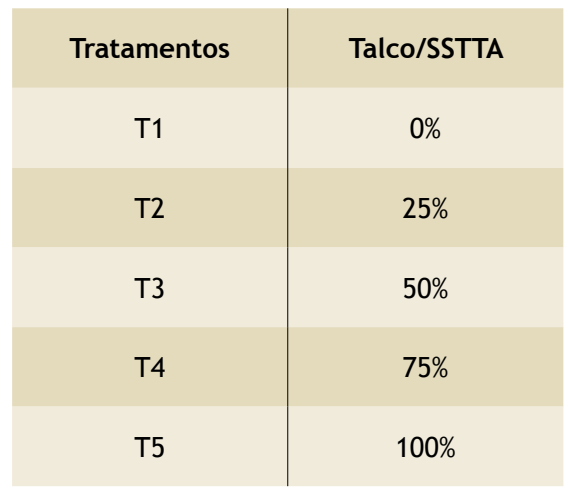

Tabela 1 - Tratamentos propostos na execução do experimento

concentrações diferentes em relação aos sólidos suspensos totais no tanque de aeração (SSTTA) (Tabela 1).

Consequentemente, na condução do experimento foram utilizados cinco biorreatores, sendo um para o tratamento sem a adição de talco (controle) e os outros quatro para os tratamentos com utilização do talco para o controle do bulking filamentoso.

Na Figura 1(a) e (b), estão representados o esquema laboratorial e os biorreatores empregados neste estudo, respectivamente.

O tempo de cada ciclo de tratamento adotado foi de 24 horas, sendo 21 horas de enchimento/rea-

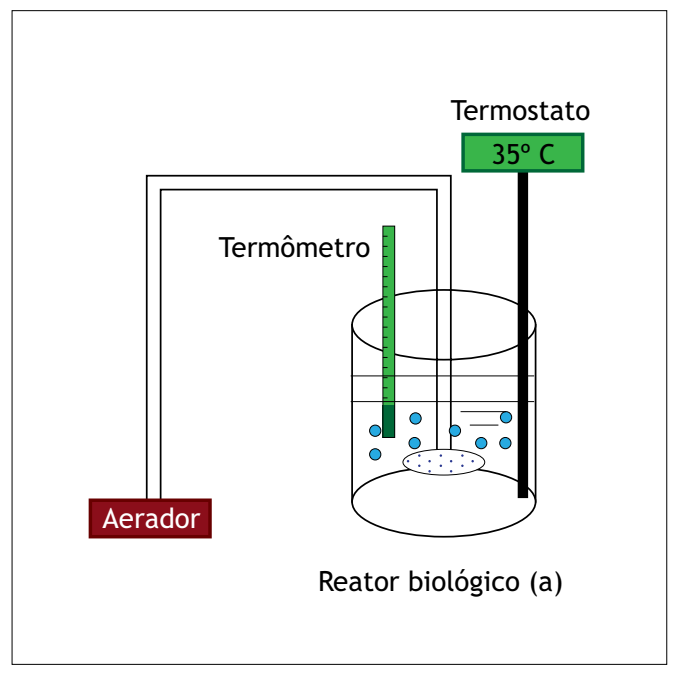

(a)

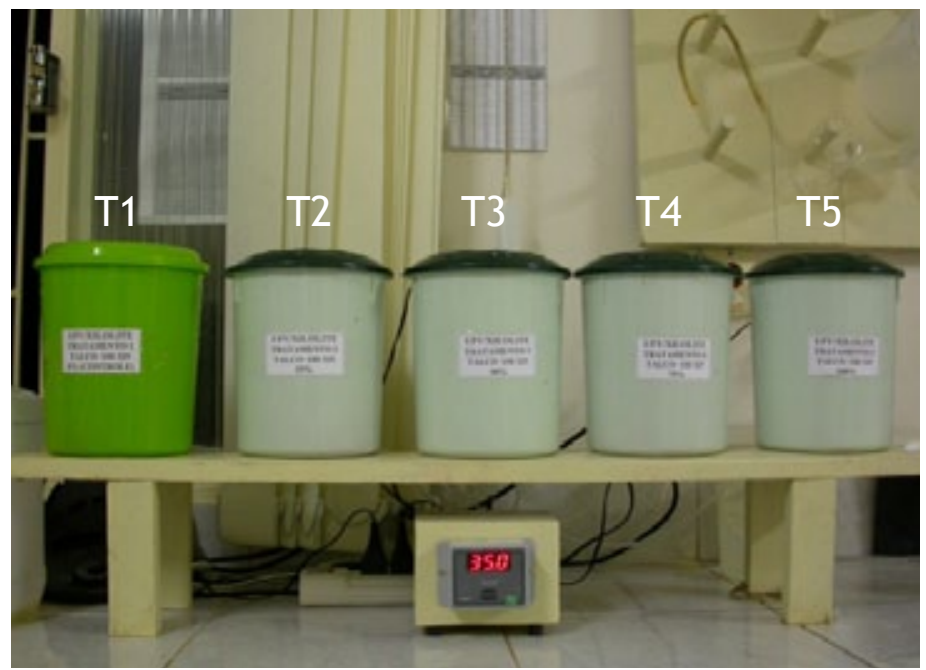

(b)

Figura 1 - (a) Esquema laboratorial e aparatos utilizados na montagem do reator em batelada sequencial (RBS) e (b) Módulos dos RBS e sequencia de tratamentos do experimento. 
ção e três horas de sedimentação/repouso. A idade do lodo foi mantida em dez dias, sendo o descarte do lodo efetuado no próprio reator, e, o oxigênio dissolvido (OD), mantido acima de 2,0 mg.L ${ }^{-1}$. O $\mathrm{pH}$ do efluente de entrada foi ajustado na faixa da neutralidade $(6,8-7,2)$ e a relação alimento/ microrganismo (A/M) mantida entre 0,2 e 0,3 $\mathrm{kgDBO}_{5} \cdot \mathrm{kgSSV}_{\mathrm{dia}}{ }^{-1}$. Como fonte de nutrientes, foi adicionado no efluente de entrada dos sistemas laboratoriais, nitrogênio na forma de uréia - $\left(\mathrm{NH}_{2}\right)_{2} \mathrm{CO}-$ e fosfato monobásico de sódio - $\left(\mathrm{NaH}_{2} \mathrm{PO}_{4} \cdot \mathrm{H}_{2} \mathrm{O}\right)$-, como fonte de fósforo, obedecendo à proporção de DBO:N:P igual a 100:5:1.

A água residuária afluente utilizada na alimentação dos reatores biológicos foi coletada na Indústria de Papel Reciclado, em operação há mais de 30 anos, localizada em Ponte Nova, Minas Gerais.

Neste trabalho, foram utilizadas amostras das águas residuárias final da máquina de papel reciclado, coletadas na canaleta de efluentes depois do tratamento primário e antes da entrada do tratamento biológico. O inóculo utilizado foi o lodo aeróbio da estação de tratamento de efluentes por lodos ativados convencional da mesma indústria onde foram coletadas as águas residuárias.
As técnicas empregadas para as análises físico-químicas das águas residuárias seguiram os procedimentos descritos no Standard Methods for Examination of Water and Wastewater (APHA, 2005). Assim, foram realizadas as análises de demanda química de oxigênio (DQO) total e filtrada, demanda bioquímica de oxigênio de cinco dias $\left(\mathrm{DBO}_{5}\right)$ total e filtrada, cor, cloretos, dureza, nitrogênio $(\mathrm{N})$ e fósforo $(\mathrm{P})$, sólidos totais $(\mathrm{ST})$, sólidos suspensos totais (SST) e sólidos dissolvidos totais (SDT), pH e condutividade elétrica (CE).

As análises da caracterização físico-química das águas residuárias quanto aos parâmetros de DQO e DBO denominadas "total" se referem à amostra bruta, ou seja, in natura. Já as análises "filtradas" das mesmas são correspondentes à amostra filtrada em membranas de fibra de vidro com diâmetro dos poros de $1,2 \mu \mathrm{m}$.

Na Tabela 2, encontram-se os valores médios das características físico-químicas das águas residuárias afluentes utilizadas na execução do experimento. As análises foram realizadas com três determinações, incluindo-se, ainda, um branco de reagentes, para avaliar possíveis contaminações.

$\mathrm{O}$ agente lastrante - talco - utilizado no experi-

\begin{tabular}{|c|c|c|c|}
\hline Parâmetros & Unidade & $\mathrm{n}$ & Valores \\
\hline DQO ${ }_{\text {total }}$ & \multirow{12}{*}{$\mathrm{mg} \cdot \mathrm{L}^{-1}$} & 60 & $3.065 \pm 427$ \\
\hline $\mathrm{DQO}_{\text {filtrada }}$ & & 60 & $2.427 \pm 363$ \\
\hline $\mathrm{DBO}_{5 \text { total }}$ & & \multirow{10}{*}{12} & $2.892 \pm 183$ \\
\hline $\mathrm{DBO}_{5}$ filtrada & & & $2.476 \pm 123$ \\
\hline Cor & & & $264 \pm 21$ \\
\hline Cloretos & & & $95 \pm 11$ \\
\hline Dureza $_{\text {total }}$ & & & $776 \pm 24$ \\
\hline $\mathrm{N}_{\text {total }}$ & & & $0,70 \pm 0,05$ \\
\hline$P_{\text {total }}$ & & & $1,41 \pm 0,03$ \\
\hline ST & & & $182 \pm 70$ \\
\hline SST & & & $152 \pm 324$ \\
\hline SDT & & & $64 \pm 25$ \\
\hline $\mathrm{pH}$ & - & 60 & $5,4 \pm 1,7$ \\
\hline CE & $\mathrm{mS} . \mathrm{cm}^{-1}$ & 60 & $2,4 \pm 0,26$ \\
\hline
\end{tabular}

Nota: $\mathrm{n}$ (número de amostras); \pm (desvio padrão) 


\begin{tabular}{|c|c|c|}
\hline $\begin{array}{c}\text { Característica } \\
\text { Físico-Química }\end{array}$ & Unidade & Valores \\
\hline pH (solução 10\%) & - & 9,0 \\
\hline Tamanho de partícula & mesh & \#325 \\
\hline Densidade aparente & g. $\mathrm{cm}^{-3}$ & 0,90 \\
\hline Densidade compactada & g. $\mathrm{cm}^{-3}$ & 1,60 \\
\hline Área específica & $\mathrm{cm}^{2} \cdot \mathrm{g}^{-1}$ & 9.000 \\
\hline Alvura (mínima) & \multirow{9}{*}{$\%$} & 94 \\
\hline Umidade (máxima) & & 1,00 \\
\hline Absorção de óleo & & 51 \\
\hline $\mathrm{MgO}$ & & 31,0 \\
\hline $\mathrm{SiO}_{2}$ & & 60,1 \\
\hline $\mathrm{CaO}$ & & 0,2 \\
\hline $\mathrm{Fe}_{2} \mathrm{O}_{3}$ & & 0,3 \\
\hline $\mathrm{Al}_{2} \mathrm{O}_{3}$ & & 1,4 \\
\hline Perda ao fogo $\left(1.000^{\circ} \mathrm{C}\right)$ & & 7,0 \\
\hline
\end{tabular}

Tabela 3 - Características físico-químicas do agente lastrante (talco)

mento é composto por silicato de magnésio hidratado $\left(3 \mathrm{MgO}^{2} 4 \mathrm{SiO}_{2} \cdot \mathrm{H}_{2} \mathrm{O}\right)$, produzido a partir de minério extraído de jazidas em Brumado-BA e beneficiado em moinhos de rolos ou vertical tipo "raymond”. O talco apresenta-se na forma de pó branco, muito fino, untuoso ao tato, inodoro e isento de asbestos. Encontra-se na Tabela 3 a composição química do talco estudado.

O controle microbiológico foi realizado por meio de amostras de lodo analisadas em microscópio de luz direta e contraste de fase nos aumentos de 100, 200, 400 e 1.000 vezes. Foram também realizadas observações microscópicas para avaliar a interação do lodo fresco e do talco.

A identificação dos microrganismos foi realizada com observações microscópicas do lodo de acordo com a chave dicotômica para determinação da espécie disponível em Jenkins et al. (2003). A técnica permite observar a forma dos filamentos e das células, bem como a relação destes com os flocos e as medidas de diâmetro e comprimento das células e filamentos.

Avaliou-se o efeito de adições de talco sobre o sistema de tratamento, com controle de sólidos por meio da manutenção da idade do lodo de dez dias. Neste sentido, foram realizadas três aplicações de talco, sendo que entre as aplicações foi observado um período de adaptação equivalente a duas idades do lodo (20 dias), neste sentido, buscou-se garantir que, ao final deste período, toda a biomassa dos reatores biológicos fosse renovada e adaptada à nova condição de tratamento.

Assim, os experimentos foram conduzidos e monitorados em escala laboratorial durante 90 dias consecutivos, sendo que foram coletadas 30 observações - o que caracteriza três repetições, de dez dias (equivalente a idade do lodo), em um delineamento inteiramente causalizado -, para cada um dos tratamentos com o intuito de avaliar o efeito do talco sobre o controle do intumescimento filamentoso.

As seguintes análises foram realizadas nos efluentes tratados: DQO (total e filtrada), $\mathrm{DBO}_{5}$ (total e filtrada), turbidez, $\mathrm{CE}$ e $\mathrm{pH}$.

As análises realizadas no lodo/reator biológico foram: sólidos suspensos totais no tanque de aeração (SSTTA), sólidos suspensos voláteis no taque de aeração (SSVTA), sólidos suspensos fixos no tanque de aeração (SSFTA), índice volumétrico do lodo (IVL), oxigênio dissolvido (OD), temperatura $\left({ }^{\circ} \mathrm{C}\right)$ e observações microscópicas.

A eficiência dos tratamentos e a sedimentabilidade do lodo foram determinadas por meio da remoção de DQO dos efluentes e do IVL, respectivamente.

Cabe destacar que o IVL é um ensaio empírico de sedimentabilidade bastante usual no controle de estações de tratamento, o qual é definido como o volume ocupado por $1 \mathrm{~g}$ de lodo após a sedimentação por trinta minutos.

Com o intuito de verificar o comportamento da sedimentabilidade do lodo, os valores de IVL ( $\left.\mathrm{mL}^{-1} \mathrm{~g}^{-1}\right)$ foram avaliados com base na faixa de valores apresentadas na Tabela 4.

As técnicas empregadas para as análises físico-químicas e biológicas dos efluentes tratados e lodo/reator biológico seguiram os procedimentos descritos em APHA (2005).

Os dados obtidos durante a fase de execução do experimento foram testados quanto à normalidade, homogeneidade e de aderência das variâncias, utilizando os testes Shapiro-Wilk e Qui-quadrado disponíveis no software Statoft Statistica ${ }^{\circledR}$ (STATSOFT, 2007).

Verificou-se que a distribuição normal não se aplicou às amostras de dados, fato já esperado conforme inúmeros exemplos na literatura especializada (OLIVEIRA, 2006). Logo, recorreu-se a um escopo de métodos inferenciais compostos por testes não paramétricos. 


\begin{tabular}{c|c}
\hline Sedimentabilidade & IVL $\left(\mathrm{mL} . \mathrm{g}^{-1}\right)$ \\
\hline Ótima & $0-50$ \\
\hline Boa & $50-100$ \\
\hline Média & $100-200$ \\
\hline Ruim & $200-300$ \\
\hline Péssima & $>300$
\end{tabular}

Fonte: METCALF \& EDDY (2003) e VON SPERLING (2011)

\section{Tabela 4 - Interpretação aproximada do índice volumétrico do lodo (IVL)}

Os resultados foram avaliados segundo análise de variância de medianas por meio do teste Kruskal-Wallis e, quando detectadas diferenças significativas entre as amostras independentes, aplicou-se o teste de comparações múltiplas, ao nível de 5\% de probabilidade, disponível no programa StatSoft Statistica ${ }^{\circledR}$.

No auxílio de apresentação, interpretação e discussão dos dados, utilizou-se gráficos "box-plot" e buscou-se inferir sobre a distribuição dos valores das variáveis monitoradas em termos de medida de posição. Além disso, este permite observar os valores mínimo, primeiro quartil, segundo quartil, terceiro quartil e valor máximo.

\section{Resultados e discussão}

O lodo utilizado durante o experimento apresentou uma concentração excessiva de bactérias filamentosas, as quais ocasionavam o intumesci- mento filamentoso (Figura 2 (a)). Esta condição foi ideal para a execução dos testes e determinação das dosagens ótimas de talco para avaliar o impacto deste no aumento da sedimentabilidade do lodo biológico.

Os flocos apresentavam-se mal formados - formatos irregulares - devido à excessiva presença de bactérias filamentosas em seu interior. No entanto, não se observou bactérias formadoras de flocos dispersas.

Devido à presença de bactérias filamentosas no interior dos flocos biológicos, estes apresentaram tamanhos variáveis, sendo sempre inferiores a 100 $\mu \mathrm{m}$.

De acordo com a escala de concentração de organismos filamentosos proposta por Jenkins et al. (2003), observou-se uma presença abundante da espécie Tipo $021 \mathrm{~N}$, sendo esta a bactéria responsável pelo intumescimento filamentoso do lodo (Figura 2(b)). Conforme destaca Sousa (2008) esta espécie de bactéria filamentosa é comumente encontrada em lodos de tratamentos biológicos de efluentes de fabricas de papel.

A bactéria Tipo $021 \mathrm{~N}$ apresenta filamentos retos ou levemente curvos, com diâmetro aproximado do filamento de $1 \mathrm{a} 2 \mu \mathrm{m}$, comprimento do filamento que podem chegar até a $5.000 \mu \mathrm{m}$ (MARTINS et al. 2004). Conforme pode ser verificado na Figura 2(a) e (b) e destacado por Bitton (2005) os filamentos geralmente estão associados aos flocos, fazendo pontes entre eles, mas podem crescer dispersos na solução do lodo. As células apresentam coloração de Gram negativa, coloração de Neisser positiva

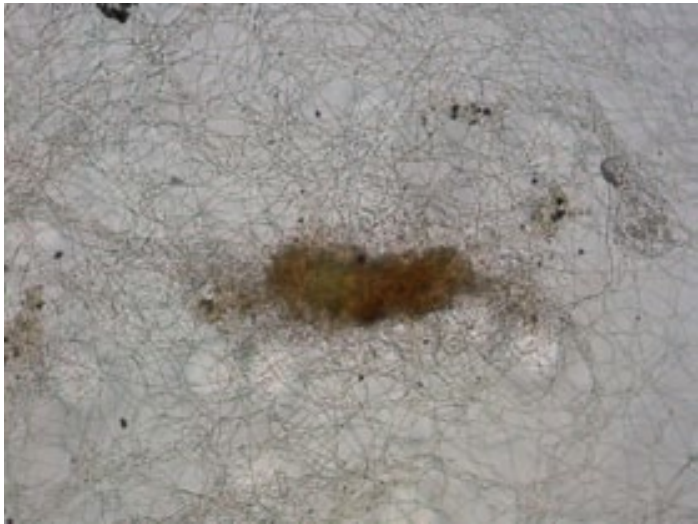

(a)

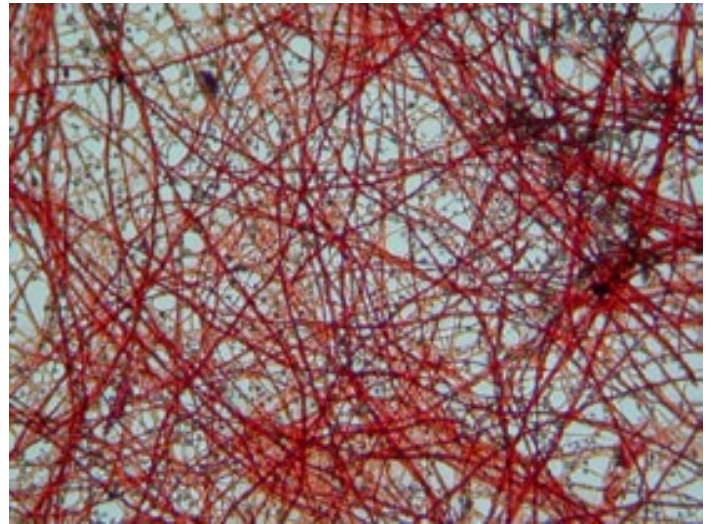

(b)

Figura 2 - Microfotografias de contraste de fase do lodo biológico utilizado no experimento: (a) amostra fresca do lodo evidenciando concentração excessiva de bactérias filamentosas (100x) e (b) amostra de lodo corada, utilizada na identificação da bactéria filamentosa Tipo $021 \mathrm{~N}(1.000 x)$. 
para as células e negativa para os filamentos, coloração de poly- $\beta$-hidroxybutirato positiva.

A bactéria Tipo $021 \mathrm{~N}$ caracteriza-se por formar pontes entre os flocos, impossibilitando a aproximação entre eles, dificultando a sedimentação do lodo. Como consequência, a manta de lodo no decantador secundário permanece ascendente, o que ocasiona grandes massas de sólidos suspensos totais no efluente tratado. Devido a essa dificuldade de interação entre os flocos ocasionada por esta espécie, o intumescimento torna-se bastante agressivo e excessivo.

Conforme Jenkins et al. (2003) e Henze et al. (2008) o crescimento desse microrganismo está associado a diversos fatores, tais como deficiência de nutrientes, principalmente nitrogênio e fósforo, presença de substratos facilmente biodegradáveis, principalmente ácidos graxos voláteis de cadeia curta e açúcares simples, e septicidade no efluente com a presença de sulfeto.

De uma maneira geral, observa-se que durante aplicação do agente lastrante - talco - (Figura 3(a)), os valores de IVL para o tratamento controle, ou seja, tratamento sem adição de talco, encontraram-se, desde o primeiro ciclo de tratamento, sempre superiores a $180 \mathrm{~mL} \cdot \mathrm{g}^{-1}$, atingido valores máximos de até $270 \mathrm{~mL} \cdot \mathrm{g}^{-1}$. Esses valores mostram que, durante a execução do experimento, o lodo biológico utilizado apresentou baixos índices de sedimentabilidade, sendo este classificado, segundo Von Sperling (2011), como ruim. Neste tratamento, devido à baixa sedimentabilidade do lodo, foram observadas perdas de sólidos junto ao efluente tratado durante a etapa de sedimentação na maioria dos ciclos.

Para os demais tratamentos, nos quais foram utilizadas concentrações crescentes de talco, após a aplicação, houve uma redução do índice volumétrico do lodo (IVL) inversamente proporcional à dosagem de talco no tanque de aeração, obtendo-se valores médios de IVL de 187,9; 154,3; 121,5 e 104,9 mL.g ${ }^{-1}$, para os tratamentos T2, T3, T4 e T5, respectivamente, estando estes classificados como de média sedimentabilidade. Cabe destacar que nos tratamento T4 e T5 foram observados valores de IVL inferiores a $100 \mathrm{~mL} \cdot \mathrm{g}^{-1}$, o que os classifica como de boa sedimentabilidade.

Para avaliar qualitativamente o efeito de adições de talco sobre o sistema biológico quanto à melhoria de sedimentabilidade do lodo, a variância das medianas de IVL obtidas em cada tratamento foi analisada e está reunida no quadro de comparações múltiplas (Figura 3(a)).
De acordo com os resultados mostrados na Figura 3(a), verificou-se a existência de diferenças estatisticamente significativas a $5 \%$ de probabilidade.

Analisando o conjunto de dados do IVL, pode-se verificar que o tratamento controle (T1), no qual não foi aplicado talco, apresentou a maior valor de mediana, caracterizando um lodo de sedimentabilidade ruim, fato este que confirma estatisticamente que a adição de talco acarreta significativas melhorias na sedimentabilidade do lodo.

Já para os tratamentos em que foram adicionadas dosagens crescentes de talco em relação aos sólidos suspensos totais no tanque de aeração (SSTTA), verifica-se que existe diferença estatisticamente significativa de sedimentabilidade em relação à dosagem aplicada nos reatores, ou seja, as medianas de valores gerais do IVL são inversamente proporcionais à dosagem de talco aplicada.

Em T2 e T3 foram verificadas reduções nas medianas dos valores do IVL, de $13,7 \%$ e $29,6 \%$, em comparação ao tratamento controle, respectivamente. No entanto, analisando o valor absoluto deste índice, pode-se afirmar que tais melhorias quanto à sedimentabilidade não são suficientes para o sistema biológico de tratamento de efluente, ficando fora do ideal (METCALF \& EDDY, 2003).

Os melhores desempenhos quanto à sedimentabilidade do lodo foram obtidos nos tratamentos com a maior dosagem de talco, tendo reduções, em relação aos valores de medianas do IVL comparado ao tratamento controle de $47,7 \%$ e $55,9 \%$, para os T4 e T5, respectivamente. Os desempenhos em redução dos valores do IVL são estatisticamente iguais nestes dois tratamentos.

Os resultados obtidos, foram semelhantes com os alcançados por Bidaut, et al. (1996) e Bidaut, et al. (1997), que verificaram os melhores efeitos de redução do IVL e, consequentemente, aumento da sedimentabilidade do lodo nos tratamentos nos quais foram aplicados as proporções de 60, 80 e 100\% de talco em relação à biomassa expressa em termos de SSTTA.

Além da redução de perda de sólidos junto ao efluente tratado, têm-se outras vantagens quanto à melhoria na sedimentabilidade do lodo. Uma delas é que o lodo com boas características de sedimentabilidade tem a possibilidade de operar com maior flexibilidade a estação, pois implica em redução da vazão de reciclo e melhorias quanto ao adensamento e desidratação do lodo (SEKA, et al., 2000; AGRIDIOTIS, et al., 2006).

Apesar de constatado o efeito em curto prazo de 
melhorias de sedimentabilidade pelo uso do talco em torno de dez dias, ele demonstrou ser um eficiente agente lastrante, que aumenta o peso e a densidade do floco biológico e poderá ser utilizado como medida corretiva, ou seja, de maneira emergencial em condições severas de intumescimento, evitando a perda da eficiência de tratamento e de clarificação do efluente tratado. Este efeito de curto prazo, também foi observado por Eikelboom e Grovenstein (1998) ao conduzirem um estudo em escala real durante duas semanas, utilizando uma mistura de talco com coagulante catiônico na proporção de $22 \%$ em relação aos SSTTA. Durante a condução do experimento, foram observadas reduções significativas no IVL de aproximadamente 900 $\mathrm{mL} . \mathrm{g}^{-1}$ para valores inferiores a $250 \mathrm{~mL} . \mathrm{g}^{-1}$, num período entre 5 e 8 dias.

Destaca-se que este tempo de efeito do talco no aumento da sedimentabilidade também é o suficiente para corrigir as causas que favorecem o crescimento excessivo das bactérias filamentosas ou para criar condições favoráveis ao crescimento das bactérias formadoras de flocos. Como exemplo, pode-se citar, segundo Metcalf \& Eddy, (2003) e Bitton (2005), o uso de medidas preventivas no controle do intumescimento do lodo como: controle das cargas orgânicas e de pH, ajuste da concentração de nutrientes e oxigênio dissolvido, uso de seletores biológicos, entre outras.

Para avaliar o efeito da influência da utilização do talco sobre a atividade biológica e, por conseguinte, a remoção de matéria orgânica, foi aplicado o teste não paramétrico de comparações múltiplas sobre os valores de medianas de eficiência de remoção de DQO nos tratamentos (Figura 3(b)).

De acordo com os resultados mostrados na Figura 3(b), verifica-se que não existem diferenças estatisticamente significativas a $5 \%$ de probabilidade entre as medianas de remoção de DQO para os tratamentos.

Todos os tratamentos removeram mais que $94 \%$ da DQO, de modo que o maior valor desse parâmetro, medido para os efluentes tratados, não chegou a 160 mg.L $\mathrm{L}^{-1}$.

Além disso, eficiências de remoção de DQO acima de $90 \%$ são superiores aos valores máximos citados por Von Sperling (2011) para sistema de tratamento biológico por lodos ativados de águas residuárias domésticas.

No entanto, estes valores de eficiência de remoção de DQO são similares aos resultados de estudos reportados por Pokhrel e Viraraghavan (2004), devido à grande biodegradabilidade da matéria orgânica proveniente de efluentes das indústrias de papel reciclado, os processos de lodos ativados podem alcançar valores de eficiência de remoção de matéria orgânica em termos de DQO superior a 93\%. Deve-se salientar que em um sistema laboratorial possui uma maior facilidade de manter o controle operacional, otimizando, assim, o tratamento.

Analisando o conjunto de dados de remoção de DQO (Figura 3(b)), pode-se verificar que não houve diferenças, ocorrendo uma homogeneidade entre os dados observados quando comparados os tratamentos. Assim, pode-se concluir que, estatisticamente, ocorreu a mesma eficiência de remoção de matéria orgânica nos cinco tratamentos.

Desta forma, fica comprovado que, qualitativamente, no tratamento controle (T1), comparado aos demais tratamentos em que foram adicionadas dosagens crescentes de talco (T2, T3, T4 e T5), não houve efeito dessa adição sobre o sistema biológico de tratamento. Comprova-se, com isso, a atuação inerte do talco sobre o sistema.

Conforme resultados obtidos por Seka, et al. (2000) e Agridiotis, et al. (2006), verificou-se que além de ser insolúvel e melhorar o balanço hidrofobicidade/hidrofilicidade, o talco não afeta a eficiência do tratamento, o que prova sua compatibilidade com a biomassa.

Para avaliar qualitativamente o efeito de adições sucessivas de talco sobre o sistema biológico quanto ao efeito sobre a biomassa, as variâncias das medianas de SSVTA obtidas em cada tratamento foram analisadas e estão reunidas na Figura 3(c).

De acordo com os resultados mostrados na Figura 3(c), verifica-se que não existem diferenças estatisticamente significativas a $5 \%$ de probabilidade entre as medianas de SSVTA para os tratamentos em cada uma das aplicações de talco.

Observa-se, pelos valores monitorados de biomassa, que estes sempre permaneceram superiores a $2.800 \mathrm{mg} \cdot \mathrm{L}^{-1}$. De acordo com Metcalf \& Eddy (2003), os valores típicos de SSVTA para sistemas de tratamento por lodos ativados de aeração prolongada variam entre 2.500 a 4.000 m. $\mathrm{L}^{-1}$.

Sistemas de aeração prolongada, como o utilizado neste estudo, têm uma grande concentração de SSVTA, ou seja, maior disponibilidade de biomassa para assimilar o substrato do efluente, resultando numa maior eficiência de remoção de carga orgânica (DQO) se comparado a outros sistemas de tratamento biológico.

Fazendo uma comparação como o tratamento 
IVL (mL. $\left.\mathbf{g}^{1}\right)$

\begin{tabular}{|c|c|c|c|c|c|}
\hline \multicolumn{4}{|c|}{ Tratamentos* } & Mediana & Média \\
\hline T1 & $\mathrm{a}$ & & & 222,8 & 221,0 \\
\hline $\mathrm{T} 2$ & $\mathrm{a}$ & b & & 192,3 & 187,9 \\
\hline T3 & & $b$ & c & 156,9 & 154,3 \\
\hline T4 & & & $c \quad d$ & 116,5 & 121,5 \\
\hline T5 & & & d & 98,2 & 104,9 \\
\hline
\end{tabular}

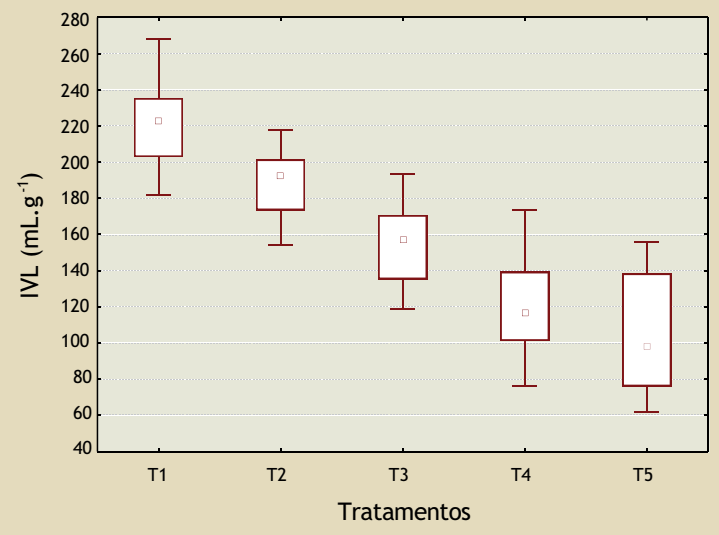

(a)

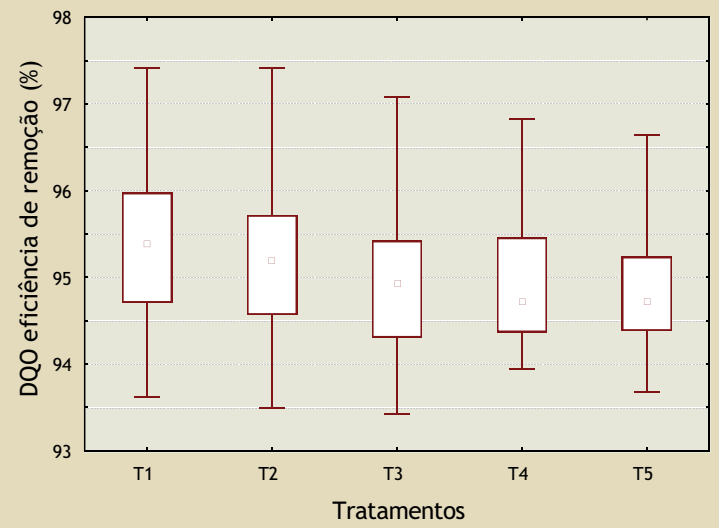

(b)

\section{SSVTA (mg. $\left.\mathrm{L}^{-1}\right)$}

\begin{tabular}{cc|c|c}
\multicolumn{2}{c|}{ Tratamentos* $^{*}$} & Mediana & Média \\
\hline T1 & a & 3407,0 & 3433,2 \\
\hline T2 & a & 3459,0 & 3474,2 \\
\hline T3 & a & 3408,0 & 3415,9 \\
\hline T4 & a & 3467,0 & 3405,3 \\
\hline T5 & a & 3504,0 & 3458,7
\end{tabular}

(c)

Legenda: Gráfico Box-plot - ${ }^{\square}$ Mediana; $\square 25 \%-75 \%$; $\square_{\text {Mínimo - Máximo }}$

*Tratamentos seguidos pela mesma letra não diferem estatisticamente ao nível de $5 \%$ de significância.

Figura 3 - Resultados dos testes de comparações múltiplas, análises descritivas e inferenciais para os parâmetros de monitoramento dos sistemas de tratamento (" $n$ " de 30 observações para cada um dos tramentos): (a) IVL (mL.g $\left.{ }^{-1}\right) ;$ (b) DQO eficiência de remoção (\%); e (c) SSVTA (mg. $\left.L^{-1}\right)$. 


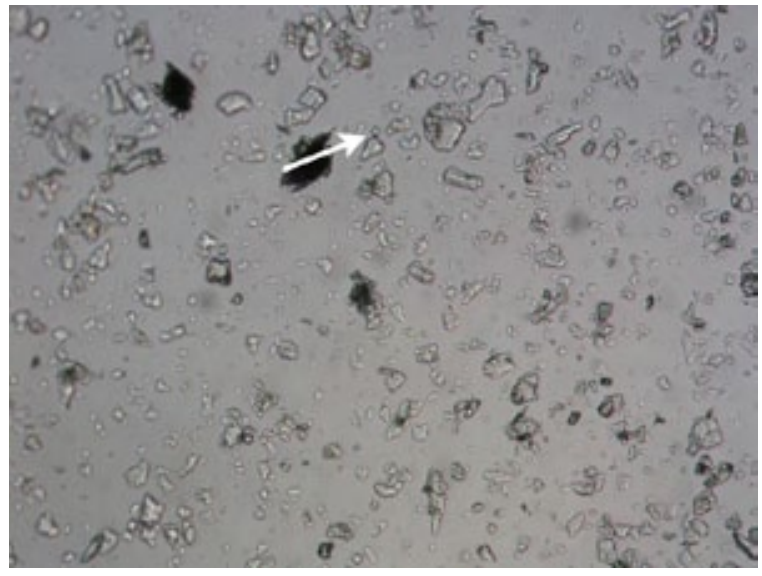

(a)

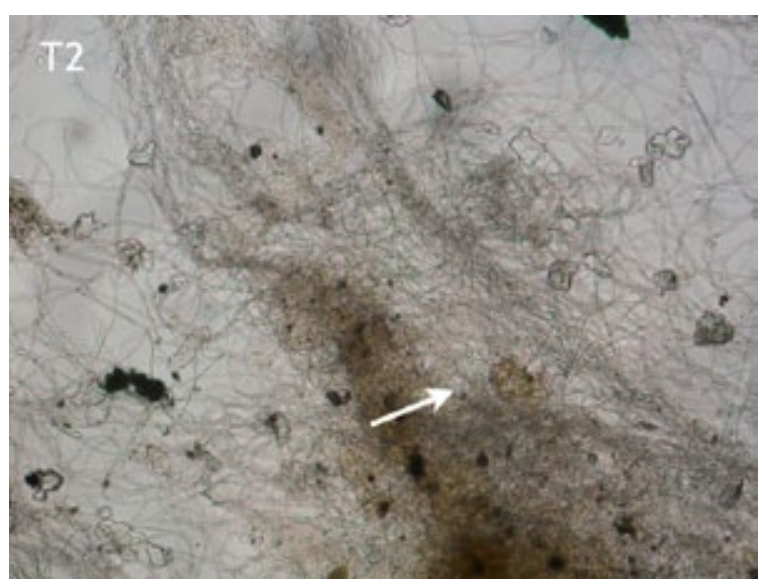

(c)

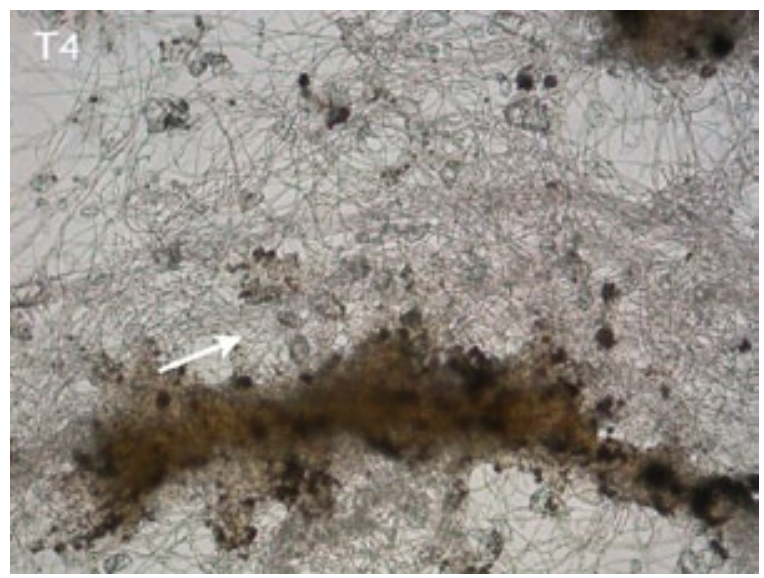

(e)

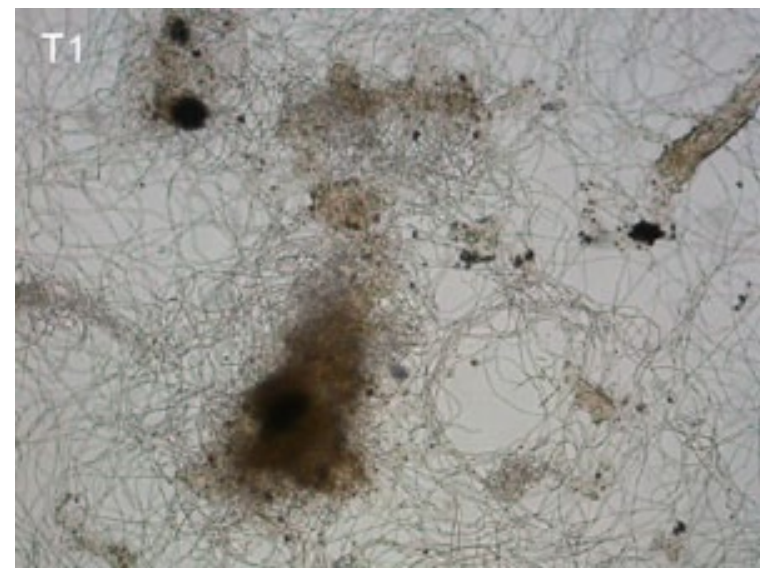

(b)

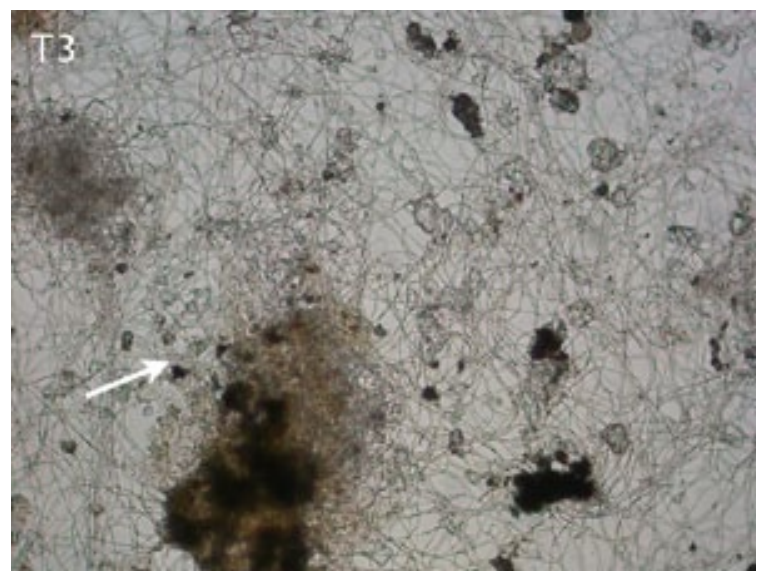

(d)

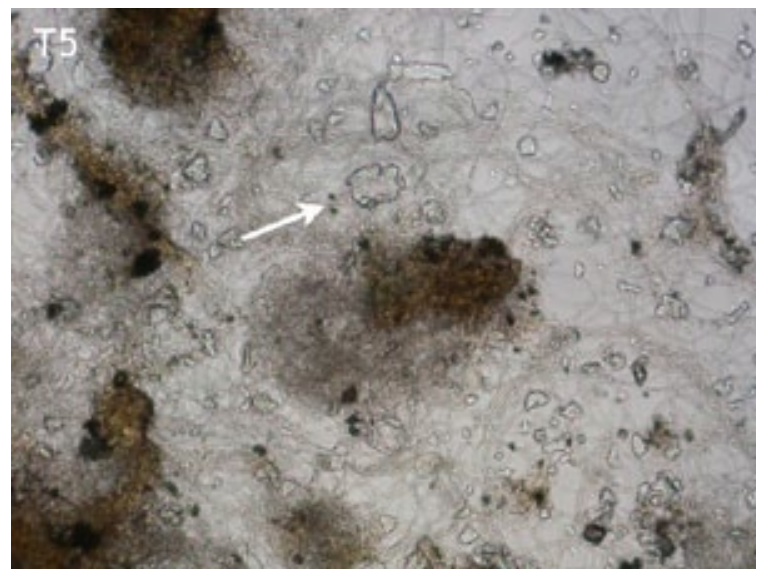

(f)

*As setas indicam os locais de interação entre o talco e os filamentos presentes no lodo biológico.

Figura 4 - Microfotografias de contraste de fase (100x), amostra fresca: (a) talco em solução de efluente utilizado neste experimento; (b) T1 = controle; (c) T2 = 25\% Talco/SSTTA; (d) T3 = 50\% Talco/SSTTA; (e) $T 4=75 \%$ Talco/SSTTA e (f) $T 5=100 \%$ Talco/SSTTA. 
controle em relação aos demais tratamentos nos quais foram aplicadas dosagens crescentes de talco, pode-se verificar que, durante todos os ciclos e em cada uma das aplicações, a concentração de biomassa não variou significativamente (Figura 3(c)).

A constatação da manutenção da concentração de biomassa é um indicativo de que o crescimento bacteriano não foi afetado pela presença de talco.

Na Figura 4(b) a (f) encontram-se as microfotografias de contraste de fase dos cinco tratamentos. Pode-se observar a concentração excessiva de bactérias filamentosas do lodo biológico em todos os tratamentos.

Conforme exposto anteriormente, de acordo com a escala de concentração de bactérias filamentosos proposta por Jenkins et al. (2003), observou-se uma presença abundante da bactéria Tipo $021 \mathrm{~N}$ (Figura 4(b)).

Na Figura 4(c) a (f) verifica-se que as partículas do talco se agregam no floco biológico, fortalecendo sua estrutura e aumentando o seu peso, de modo a facilitar sua sedimentação, caracterizando-se, assim, como um agente lastrante. Com isso, há uma queda nos valores de IVL dos tratamentos em que o talco está presente.

De acordo com Bidault et al. (1996); Graja et al. (1998) e Clauss et al. (1999), essa agregação hidrofóbica das partículas de talco junto ao floco biológico se deve à presença de exopolissacarídeos (EPS) dentro da matriz do floco biológico. Os EPS são compostos por várias substâncias, como proteínas, ácidos nucléicos e lipídeos, possuindo características hidrofóbicas.

Também pode ser constatado que o talco modificou estruturalmente a floculação, sobretudo devido ao seu peso, agindo de forma que os filamentos das bactérias foram atraídos e aderidos ao lodo devido à afinidade específica entre o talco e os EPS, contribuindo para a formação de flocos grandes e pesados, o que vai ao encontro dos resultados obtidos por Bidault et al. (1997). Neste mesmo estudo, os autores verificaram que o talco é atraído para dentro da matriz do floco, sendo colonizado pelas bactérias e interagindo com a matriz extracelular, formando um biofilme, mecanismo de interação entre o floco e o talco chamado de "floco nucleação".

\section{Conclusões e considerações finais}

As principais conclusões deste estudo são:

- A bactéria filamentosa Tipo $021 \mathrm{~N}$ foi encontrada abundantemente em todas as fases de execução do experimento, sendo a responsável por um intumescimento filamentoso excessivo do lodo biológico proveniente de uma fábrica de papel reciclado, utilizado neste estudo.

- Houve uma redução do IVL inversamente proporcional à dosagem de talco aplicada e, estatisticamente, foi verificado o efeito em curto prazo do talco na melhoria da sedimentabilidade sobre o sistema de tratamento, sendo necessária, após dez dias, uma nova aplicação de talco para controlar o intumescimento filamentoso.

- Melhores desempenhos quanto à sedimentabilidade do lodo foram obtidas nos tratamentos com a maior dosagem de talco em relação aos SSTTA , tendo reduções do IVL em relação ao controle de $47,7 \%$ e $55,9 \%$, para os tratamentos T4 (Talco/SSTTA:75\%) e T5 (Talco/SSTTA: $100 \%)$, respectivamente. As medianas de valores do IVL são estatisticamente iguais nestes dois tratamentos;

- Estatisticamente, comprovou-se que, qualitativamente, no tratamento controle (T1), comparado aos demais tratamentos em que foram adicionadas quantidades crescentes de talco (T2, T3, T4 e T5), não houve efeito algum sobre a eficiência de remoção de matéria orgânica em termos de DQO, sendo esta eficiência superior a 94,9\% em todos os tratamentos.

- Foi constatado que, durante todos os ciclos, a concentração monitorada de biomassa, expressa em termos de SSVTA, permaneceu superior a $2.800 \mathrm{mg} . \mathrm{L}^{-1} \mathrm{em}$ todos os tratamentos, indicando que o crescimento bacteriano não foi afetado pela presença de talco;

- Por meio de análises microscópicas e da composição do lodo, verificou-se que as partículas de talco foram incorporadas ao floco biológico, fortalecendo sua estrutura e aumentando o seu peso, sendo possível, portanto, considerá-lo um agente lastrante. Além disso, percebeu-se que o talco passou a fazer parte da composição da biomassa do tratamento biológico.

Os resultados apontaram que o talco poderá ser utilizado como medida corretiva, ou seja, de maneira emergencial em condições severas de intumescimento, podendo ser aplicado diretamente no reator biológico, evitando a perda da eficiência de tratamento e de clarificação do efluente tratado. Além disso, por fazer parte do processo produtivo da fabricação do papel, não serão necessários grandes investimentos em infraestrutura e logística para a obtenção do talco.

Apesar de comprovado o potencial de uso do 
agente lastrante - talco - no controle do intumescimento filamento, cabe destacar que não foi possível avaliar o impacto da adição de talco sobre todos os parâmetros de monitoramento de um sistema de tratamento por lodos ativados. Neste sentido, torna-se importante a condução de estudos em escala real com o intuito de avaliar o efeito do aumento na carga e na taxa de aplicação de sólidos (TAS) no decantador secundário. Além disso, também é importante que seja verificado seu efeito sobre a taxa de transferência de oxigênio à biomassa, que pode ser prejudicada devido à presença de valores de sólidos elevados no reator biológico.

\section{Agradecimentos}

Os autores agradecem a Xilolite S.A. pela disponibilização do talco; à Klabin Papéis e Embalagens - Unidade Ponte Nova/MG - pelo fornecimento do lodo biológico e as águas residuárias; à Fundação de Amparo à Pesquisa do Estado de Minas Gerais (Fapemig) pelo financiamento do projeto intitulado "Uso de Talco no Controle do Intumescimento Filamentoso no Tratamento de Efluentes de Fábrica de Papel Reciclado" (Processo 5694-6.01/07) por meio do qual foi possível a realização do experimento e obtenção dos dados apresentados no presente artigo e ao Conselho Nacional de Desenvolvimento Científico e Tecnológico (CNPq) pela concessão do auxílio - bolsa de estudo -, concedida ao primeiro autor, por intermédio do Programa de Pós-Graduação em Ciência Florestal da UFV - Campus Viçosa.

\section{Referências}

AGRIDIOTIS, V.; FCIWEM, C. F. F.; BALAVOINE, C. W.; CARLIELL-MARQUET, C. An examination of the surface characteristics of activated sludge in relation to bulking during the treatment of paper mill wastewater. Water and environment, v 2, p 123 130. 2006.

AMERICAN PUBLIC HEALTH ASSOCIATION (APHA). Standard methods for examination of water and wastewater. Washington: APHA, AWW, WPCF. 21. ed. 2005.

BIDAUT, A.; CLAUSS, F.; HELAINE, D.; BALAVOINE, C. Floc agglomeration and structuration by a specific talc mineral composition. Water Science and Technology, v. 36, n 4, p 57 - 68, 1996.

BIDAUT, A.; CLAUSS, F.; HELAINE, D.; BALAVOINE, C. Improving activated sludge floc structure and aggregation for enhaced setting and thickening per- formances. Water Science and Technology, v. 38, n 8 - 9, p 35 - 44, 1997.

BITTON, G. Wastewater microbiology. Wiley-Liss. 3 ed. Inc. . USA. 746p. 2005.

CAMARA, A. L. Uso de talco nacional como aditivo adsorvente de piches e materiais pegajosos no processo de fabricação do papel. 2003, 162 p. Dissertação (Mestrado). Curso de Pós-Graduação em Engenharia Metalúrgica e de Minas da Universidade Federal de Minas Gerais, Belo Horizonte, 2003.

CLAUSS, F.; BALAVOINE, C.; HÉLAINE, D.; MARTIN, $G$. Controlling the setting of activated sludge in pulp and paper wastewater treatment plants. Water Science and Technology, v. 40, n 11 - 12, p 223 230, 1999.

GRAJA, S., CLAUSS, F., WILDERER, P. Application of talc to improve settleability of activated sludge. In: Proceedings the Development and Application of Waste Technology. Annals ‥1998. Munich, DE, July $1-3$.

CRUZ M. P.; BARBOSA, L. C. A.; MALTHA, C. R. A.; GOMIDE, J. L.; MILANEZ, A. F.. Caracterização química do "pitch" em indústria de celulose e papel de eucalyptus. Quimica Nova, v. 29, n.3, p 459-466, 2006.

EIKELBOOM, D. H.; GROVENSTEIN, J. Control of bulking in a full scale plant by addition of talc (PE8414). Water Science and Technology, v. 37, n 4 - 5, p 297 - 301, 1998.

HENZE, M.; VAN LOOSDRECHT, M. C. M.; EKAMA G.A.; BRDJANOVIC, D. Biological wastewater treatment: principles, modelling and design. IWA Publishing, 2008. 511p.

METCALF \& EDDY. Wastewater engineering: treatment and reuse. 4. ed. Metcalf \& Eddy, Inc., 2003. $1.540 \mathrm{p}$.

JENKINS, D.; RICHARD, M. G.; DAIGGER, G. T. Manual on the causes and control of activated sludge bulking and foaming. Michigan USA: Lewis Publisher, 3 ed, 2003. 190p.

LOURES, A. P. S. Tratamento anaeróbio de efluentes de máquina de papel por biorreator convencional e biorreator a membranas. 2007, 105f. Tese (Doutorado em Ciência Florestal), Departamento de Engenharia Florestal, Universidade Federal de Viçosa, Viçosa, 2007.

MARTINS, A. M.P.; PAGILLA, K.; HEIJNEN J. J.; VAN 
LOOSDRECHT, M. C.M. Filamentous bulking sludge - a critical review. Water Research, v. 38, p 793 817, 2004.

MAMAIS, D.; KALAITZI, E.; ANDREADAKIS, A. Foaming control in activated sludge treatment plants by coagulants addition. Global NEST Journal, v. 13, $n^{\circ} 3$, p $237-245,2011$.

OLIVEIRA, S. M. A. C. Análise de desempenho e confiabilidade de estações de tratamento de esgotos. 2006. 321p. Tese (Doutorado em Saneamento, Meio Ambiente e Recursos Hídricos). Escola de Engenharia da Universidade Federal de Minas Gerais, Belo Horizonte, 2006.

STATSOFT. Inc.(versão 8.0) [Programa de computador]. Tulsa, USA: Statsoft, Inc., 2007.

PACHECO, E. P.; PESSÔA, C. A. Tratamento de esgotos domésticos. Rio de Janeiro: Abes, 5 ed. 2009. 940p.

PIIRTOLA, L.; HULTMAN, B.; ANDERSSON, C.; LUNDEBERG, Y. Activated sludge ballasting in batch tests. Water Research, v. 33, p 1799 - 1804, 1999 (a).

PIIRTOLA, L., HULTMAN, B.; WEÂ N, M. L. Activated sludge ballasting in pilot plant operation. Water Research, v. 13, p 3026 - 303, 1999 (b).

POKHREL, D; VIRARAGHAVAN, T. Treatment of pulp and paper mill wastewater - a review. Science of the Total Environment, v. 333, p 37 - 58, 2004.

SANT'ANNA JÚNIOR, G. P. Tratamento biológico de efluentes: fundamentos e aplicações. Rio de Janeiro: Interciências, 2010. 418p.

SEKA, A. M.; WIELE, T.V.; VERSTRAETE, W. Feasibility of a multi-component additive for efficient control of activated sludge filamentous bulking. Water Research, v. 35.p 2995 - 3003, 2000.

SOUSA, C. A. Tratamento termofílico aeróbio de efluente de máquina de papel utilizando biorreator a membranas. 2008, 127f. Tese (Doutorado Ciência Florestal), Departamento de Engenharia Florestal, Universidade Federal de Viçosa, Viçosa, 2008.

VON SPERLING, M. Princípios básicos do tratamento de esgotos. In: VON SPERLING, M. (Org.). Princípios do tratamento biológico de águas residuárias. v. 2, 6 reimpressão. Belo Horizonte: Departamento de Engenharia Sanitária e Ambiental da UFMG, $2011.452 \mathrm{p}$.

\section{SOBRE OS AUTORES}

\section{Hygor Aristides Victor Rossoni*}

Engenheiro Ambiental e Mestre em Ciência Florestal pela Universidade Federal de Viçosa (UFV). Doutorando em Saneamento, Meio Ambiente e Recursos Hídricos da Universidade Federal de Minas Gerais (UFMG). Professor do Instituto de Ciências Exatas e Tecnológicas da UFV - Campus Florestal, Florestal, Minas Gerais, Brasil.

\section{Ana Augusta Passos Resende}

Graduada em Engenheira Civil e Mestre em Saneamento, Meio Ambiente e Recursos Hídricos pela UFMG. Doutora em Engenharia Agrícola pela UFV. Professora Adjunta do Departamento de Engenharia Civil, UFV - Campus Viçosa, Viçosa, Minas Gerais, Brasil.

\section{Ann Honor Mounteer}

Graduada em Ciências Biológicas pela McGill University, Mestre em Engenharia Ambiental e de Recursos Naturais pela State University of New York e Mestre em Ciência Florestal pela UFV. Doutora em Microbiologia Agrícola pela UFV. Professora Associada do Departamento de Engenharia Civil, UFV - Campus Viçosa, Viçosa, Minas Gerais, Brasil. Pesquisadora nível II do CNPq.

\section{Cláudio Arcanjo de Sousa}

Engenheiro Florestal, Mestre e Doutor em Ciência Florestal pela UFV. Professor Adjunto da Faculdade de Ciências Biológicas e Ambientais da Universidade Federal da Grande Dourados (UFGD), Dourados, Mato Grosso do Sul, Brasil.

\section{Cláudio Mudado Silva}

Engenheiro Civil e Mestre em Saneamento, Meio Ambiente e Recursos Hídricos pela UFMG. PhD em Engenharia Química pela University of Toronto. Professor Adjunto do Departamento de Engenharia Florestal, UFV - Campus Viçosa, Viçosa, Minas Gerais, Brasil. Pesquisador nível II do CNPq.

\section{José Lívio Gomide}

Graduado em Engenharia Florestal pela Universidade Federal do Paraná, Mestre em Science Forestry, University of Maine at Orono. Doutor of Philosophy, North Carolina State University . Professor Titular do Departamento de Engenharia Florestal, UFV - Campus Viçosa, Viçosa, Minas Gerais, Brasil. Pesquisador nível II do CNPq.

\section{Mônica de Abreu Azevedo}

Graduada em Engenheira Civil pela UFV e Mestre em Saneamento, Meio Ambiente e Recursos Hídricos pela UFMG. Doutora em Engenharia Hidráulica e Saneamento pela Universidade de São Paulo (USP). Professora Adjunta do Departamento de Engenharia Civil, UFV - Campus Viçosa, Viçosa, Minas Gerais, Brasil.

*Endereço para Correspondência: UFV - Campus Florestal / Central de Ensino e Desenvolvimento Agrário de Florestal (Cedaf). Rodovia LMG, 318 - km 6. Florestal - MG. CEP: 35690-000. Tel: +55 (31) 3536 - 3385. Fax:+55 (31) 3536 - 3361 e-mail: rossoni@ufv.br. 


\section{O site da revista DAE está repleto de novidades}

ASSINE GRATUITAMENTE O BOLETIM ELETRÔNICO, É SÓ SE CADASTRAR
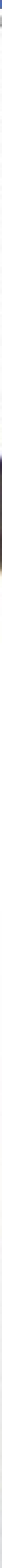